\title{
Candida zemplinina sp. nov., an osmotolerant and psychrotolerant yeast that ferments sweet botrytized wines
}

\author{
Matthias Sipiczki
}

Correspondence

Matthias Sipiczki

lipovy@tigris.klte.hu

\section{INTRODUCTION}

During the first few days of the spontaneous fermentation of grape must, a rapid succession of yeast species can be observed (e.g. Heard \& Fleet, 1985; Farkaš, 1988; Schutz \& Gafner, 1994; Sipiczki et al., 2001). Most of these species soon pass into a decline phase and become a minor component of the yeast flora. Candida stellata, a common member of the early populations, may remain active throughout most of the alcoholic fermentation, much longer than most other non-Saccharomyces yeasts. Its presence during fermentation is thought to contribute to a more complex and better aroma of the wine because of the higher production of specific aroma compounds (Soden et al., 2000) and glycerol (Ciani et al., 2000) and interactions with Saccharomyces cerevisiae in the production and degradation of metabolites (Ciani \& Ferraro, 1998). Since its growth rate is significantly lower than that of Saccharomyces cerevisiae (Ciani et al., 2000) and its cells are sensitive to ethanol (Constanti et al., 1998), C. stellata is usually overgrown by more ethanol-tolerant Saccharomyces strains.

Through years of investigation of the microflora of Tokaj wines, C. stellata has been found to be a regular component of the yeast biota of fermenting musts prepared from botrytized grapes. Tokaj, a wine region located in the

The GenBank accession number for the partial 26S rDNA sequence of Candida zemplinina $10-372^{\top}$ is AY 160761 ; the GenBank accession numbers for the ITS1-5.8S-ITS2 sequences of Candida stellata CBS $157^{\top}$ and C. zemplinina $10-372^{\top}$ are AY160766 and AY160762, respectively. northeast corner of Hungary across from East Slovakia, is one of Europe's major producers of botrytized white wines. The most characteristic products of the region are sweet dessert wines, which are usually fermented at low temperatures. The frequent occurrence of C. stellata in the samples is in agreement with earlier works that demonstrated that this yeast was normally associated with overripe and botrytized grape berries and musts obtained from botrytized grapes (e.g. Rosini et al., 1982; Jackson, 2000). Interestingly, many of our isolates identified by conventional taxonomic methods as C. stellata turned out to be much more osmotolerant and psychrotolerant than CBS $157^{\mathrm{T}}$, the type strain of C. stellata. In this work, four isolates obtained from different wineries were subjected to a more detailed physiological and molecular analysis. Conventional taxonomic tests revealed very few differences between these isolates and the C. stellata strains CBS $157^{\mathrm{T}}$ and DBPVG 6715 (CBS 843). However, considerable differences were found between their nucleotide sequences in the $26 \mathrm{~S}$ and 5.8S-ITS rDNA regions, which strongly suggests that the four isolates represent a distinct yeast species.

\section{METHODS}

Yeast strains and culture media. C. stellata CBS $157^{\mathrm{T}}$ was purchased from the Centraalbureau voor Schimmelcultures, Delft, The Netherlands. C. stellata DBPVG 6715 (CBS 843) was provided by the Industrial Yeast Collection, Dipartimento di Biologia Vegetale, Perugia, Italy. Saccharomyces cerevisiae S288c and Saccharomyces bayanus NCAIM Y00803 ${ }^{\mathrm{T}}\left(\mathrm{CBS} 380^{\mathrm{T}}\right)$ were obtained from the Yeast Genetic Stock, Berkeley, CA, USA, and the National Collection of Agricultural and Industrial Microorganisms, Budapest, Hungary, respectively. 
Yeast cultures were maintained on YPGA (1\% yeast extract, $1 \%$ peptone, $2 \%$ glucose, $2 \%$ agar; w/v). The compositions of the culture media used for taxonomic tests are given by van der Walt \& Yarrow (1984). To examine growth at various temperatures and concentrations of sugar and ethanol, cultures were grown in YPGL (YPGA without agar) supplemented as required.

Wine yeast isolation and taxonomic tests. Samples of fermenting must were taken aseptically, diluted and streaked onto YPGA plates. After incubation for 7 days at $25^{\circ} \mathrm{C}$, individual colonies were isolated. The procedures for morphological observation, fermentation, assimilation and other growth tests standard to yeast taxonomy were performed as described by van der Walt \& Yarrow (1984) and Barnett et al. (1990).

Growth under various conditions. The effect of environmental conditions on growth was examined in YPGL $(50 \mathrm{ml}$ medium in a $100 \mathrm{ml}$ flask) inoculated with cells of overnight cultures $\left(\mathrm{OD}_{660}\right.$ of $0 \cdot 1)$ and incubated on a rotary shaker. The effect of temperature was examined by comparing growth at $10,20,26$ and $32^{\circ} \mathrm{C}$. To test the effect of the presence of ethanol and higher concentrations of sugar $\left(\right.$ at $25^{\circ} \mathrm{C}$ ), the medium was supplemented with various amounts of ethanol and glucose, respectively. The increase in cell number was determined by measuring the optical density of the cultures at $660 \mathrm{~nm}$.

Microscopy. Cell morphology was examined by differential interference contrast microscopy. Photographs were taken using an Olympus BH-2 microscope.

PCR and sequence analysis. Cultures used for DNA extraction were grown overnight at $25^{\circ} \mathrm{C}$ in $10 \mathrm{ml}$ of YPGL on a rotary shaker. The cells were harvested by centrifugation, washed once with distilled water, resuspended in $0 \cdot 2$ citrate/phosphate buffer ( $\mathrm{pH} 5 \cdot 6$ ) containing $4 \mathrm{mg}$ Zymolyase $\mathrm{ml}^{-1}$ and incubated at room temperature for $1-1 \cdot 5 \mathrm{~h}$. Genomic DNA was then isolated and purified as described for Schizosaccharomyces pombe (Heyer et al., 1986).

The D1/D2 domains at the $5^{\prime}$ end of the large-subunit 26S rRNA genes were amplified in both directions with primers NL-1 and NL-4 (O'Donnell, 1993). The ITS1-5·8S-ITS2 regions were amplified with primers ITS1 and ITS4 (White et al., 1990). Amplification was performed for 36 cycles with an initial denaturation at $94{ }^{\circ} \mathrm{C}$ for $2 \mathrm{~min}$, followed in subsequent cycles by a denaturation at $91^{\circ} \mathrm{C}$ for $1 \mathrm{~min}$, annealing at $60^{\circ} \mathrm{C}(26 \mathrm{~S} \mathrm{rDNA})$ or $52^{\circ} \mathrm{C}$ (ITS1-5.8S-ITS2) for $1 \mathrm{~min}$ and a final extension at $72{ }^{\circ} \mathrm{C}$ for $15 \mathrm{~min}$. The amplification mixture consisted of $10 \mu \mathrm{l}$ buffer, $4 \mu \mathrm{ldNTP}, 10 \mu \mathrm{MgCl}_{2}, 1 \cdot 2 \mu \mathrm{l}$ primers, $0 \cdot 4 \mu \mathrm{l}$ Taq DNA polymerase (MBI Fermentas) and $10 \mu \mathrm{l}$ genomic DNA $(1 \mu \mathrm{g})$. A PTC100 (MJ Research) thermal cycler was used.

For sequencing, the amplified DNA was separated from the primers by electrophoresis and re-isolation of the fragment from the gel. Both strands of the fragments were sequenced with an ABI PRISM 3700 (Applied Biosystems) sequencer using the PCR primers. At least three sequencing reactions were performed for each amplified sample.

Sequence similarity searches were performed using the BLAST network service of the NCBI database (http://www.ncbi.nlm.nih.gov/blast). For multiple alignment of sequences, the CLUSTAL W 1.7 algorithm (Thompson et al., 1994) was used. The phylogenetic analysis was carried out using the Fitch-Margoliash method in the PHYLIP software package, version 3.5c (Felsenstein, 1993). Confidence limits for phylogenetic trees were estimated from bootstrap analysis (100 replications; SEQBOOT and CONSENSE of the PHYLIP package). Phylogenetic trees were visualized with the TREEVIEW program (Page, 1996).

\section{RESULTS AND DISCUSSION}

\section{Taxonomic characterization of the four yeast isolates}

Four yeast strains $\left(10-372^{\mathrm{T}}, 10-373,10-374\right.$ and $\left.10-375\right)$ isolated in 2001 from fermenting sweet botrytized musts in different wineries in the Tokaj wine region and deposited in the National Collection of Agricultural and Industrial Microorganisms (under strain numbers NCAIM Y016667 ${ }^{\mathrm{T}}$, NCAIM Y016668, NCAIM Y016669 and NCAIM Y016670, respectively) were selected for this study. All of them utilized lysine as a nitrogen source and fermented sucrose, but could not grow on ethanol or nitrate or at $37^{\circ} \mathrm{C}$, suggesting that they belonged to C. stellata (Barnett et al., 1990). However, the strains grew on media supplemented with concentrations of glucose high enough to inhibit C. stellata CBS $157^{\mathrm{T}}$ growth. Since no reports have been published on C. stellata strains with a similarly high degree of osmotolerance, the isolates were re-tested for assimilation and fermentation of the carbon and nitrogen sources listed in Barnett et al. (1990). For comparison, two C. stellata strains were used, CBS $157^{\mathrm{T}}$ and a collection strain, DBPVG 6715 (CBS 843). The latter strain had been isolated from wine as an osmophilic yeast (Krumbholz, 1931). The tests revealed two differences: in contrast to the C. stellata strains, the Tokaj isolates grew on YPGA supplemented with 50 or $60 \%$ $(w / v)$ glucose and also, weakly, on sorbose.

The Tokaj isolates also differed from C. stellata in their morphology and acid production. On morphology agar, they formed flat, white, glossy colonies with smooth to finely lobed margins and a butyrous texture. The colonies of C. stellata CBS $157^{\mathrm{T}}$ and DBPVG 6715 were usually smaller and dull with a raised centre. After 3 days incubation on morphology agar at $25^{\circ} \mathrm{C}$, the cells of the Tokaj isolates were oval or elongated $(2 \cdot 2-3 \cdot 0 \times 3 \cdot 0-5 \cdot 2 \mu \mathrm{m})$, whereas the cells of the C. stellata strains were round and larger $(4 \cdot 4-6 \cdot 1 \mu \mathrm{m}$ in diameter) (Fig. 1). The haloes produced on chalk agar were much wider around the colonies of the Tokaj isolates than around the colonies of C. stellata CBS $157^{\mathrm{T}}$ and DBPVG 6715, indicating that the former strains produced more acid. In view of the morphological and physiological differences between them, the Tokaj isolates appear to represent a species distinct from C. stellata; the name Candida zemplinina is proposed for this new species. No sporulation was detected in cultures of C. zemplinina grown on sporulation media.

\section{Latin diagnosis of Candida zemplinina sp. nov. Sipiczki}

In agaro morphologico post dies 3 ad $25^{\circ} \mathrm{C}$, cellulae vegetativae ellipsoidae aut elongatae $(2 \cdot 2-3 \cdot 0 \times 3 \cdot 0-5 \cdot 2 \mu \mathrm{m})$, singulae et binae, per gemmationem multipolarem reproducentes. Pseudohyphae nullae; hyphae verae non fiunt. Ascosporae non fiunt post 25 dies $25{ }^{\circ} \mathrm{C}$ in agaro farina maydis confecto se PDA seu medio Gorodkowae. In agaro morphologico post dies 7 ad $25^{\circ} \mathrm{C}$, incrementum fuscum pallidum, butyrosum; 

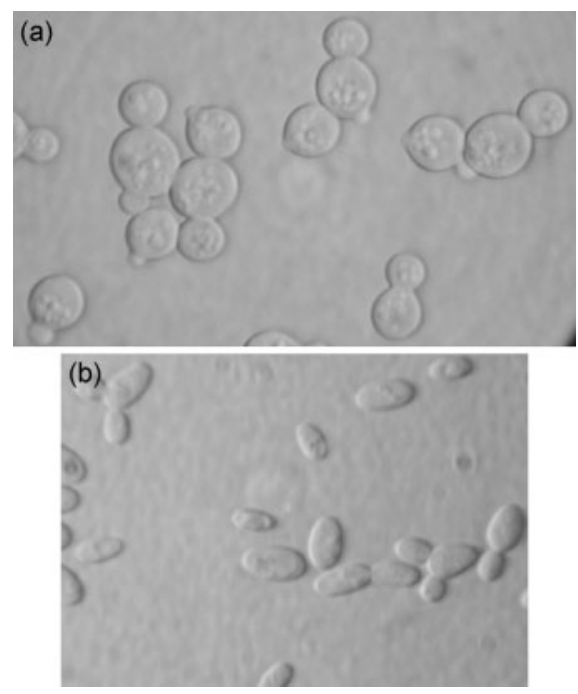

Fig. 1. Cell morphology. Photomicrographs of (a) C. stellata CBS $157^{\top}$ and (b) C. zemplinina $10-372^{\top}$ grown in yeast extract/peptone supplemented with $2 \%$ glucose. Bar, $5 \mu \mathrm{m}$.

centrum colonia planum; margo glabro vel undulato. Glucosum, sucrosum et raffinosum fermentantur. Galactosum, maltosum et lactosum non fermentantur. Assimilantur glucosum, sucrosum, L-sorbosum (infirme), raffinosum et lysinum. Non assimilantur galactosum, D-glucosaminum, D-ribosum, D-xylosum, L-arabinosum, D-arabinosum, Lrhamnosum, maltosum, trehalosum, methyl $\alpha$-D-glucosidum, cellobiosum, salicinum, melibiosum, lactosum, melezitosum, inulinum, amylum solubile, glycerolum, erythritolum, ribitolum, D-glucitolum, D-mannitolum, galactitolum, inositolum, glucono-D-lactonum, acidum succinicum, acidum citricum, methanolum, ethanolum, potassi nitras, cadaverinum et $N$-acetyl-D-glucosaminum. Vitaminae externae ad crescentiam necessaria sunt. Crescit in medio cum $60 \%(\mathrm{w} / \mathrm{v})$ glucoso. Non crescit in medio $10 \mu \mathrm{g}$ cycloheximido $\mathrm{ml}^{-1}$ addito. Augmentum non fiunt in temperatura $37^{\circ} \mathrm{C}$.

Typus: $10-372^{\mathrm{T}}$. Isolata a vinum album ex Zemplin, Hungaria. In collectione zymotica Centraalbureau voor Schimmelcultures, Trajectum ad Rhenum, sub no. CBS $9494^{\mathrm{T}}$ deposita est.

\section{Description of Candida zemplinina sp. nov. Sipiczki}

Candida zemplinina (zem.pli.ni' na. N.L. n. zemplinina refers to the Zemplin mountain range, the south and south-east facing slopes of which constitute the Tokaj wine region).

On morphology agar, after 3 days incubation at $25^{\circ} \mathrm{C}$, cells are ellipsoid to elongated $(2 \cdot 2-3 \cdot 0 \times 3 \cdot 0-5 \cdot 2 \mu \mathrm{m})$ and occur singly and in pairs. Budding is multilateral. Neither hyphae nor pseudohyphae are produced. No ascospores are observed after 25 days incubation at $25^{\circ} \mathrm{C}$ on corn-meal agar, potato dextrose agar or Gorodkowa agar. On morphology agar, after 7 days incubation at $25^{\circ} \mathrm{C}$, colonies are low and colony margins are smooth to finely lobed. The texture of the colonies is butyrous. Ferments glucose, sucrose and raffinose. Does not ferment galactose, maltose and lactose. Assimilates glucose, sucrose, L-sorbose (slowly), raffinose and lysine. Does not assimilate galactose, D-glucosamine, D-ribose, D-xylose, L-arabinose, D-arabinose, L-rhamnose, maltose, trehalose, methyl $\alpha$-D-glucoside, cellobiose, salicin, melibiose, lactose, melezitose, inulin, starch, glycerol, erythritol, ribitol, D-glucitol, D-mannitol, galactitol, inositol, D-glucono-1,5-lactone, succinate, citrate, methanol, ethanol, potassium nitrate, cadaverine, $N$-acetylD-glucosamine and lysine. No growth occurs in vitaminfree medium. Growth occurs in the presence of $60 \%(\mathrm{w} / \mathrm{v})$ glucose. No growth occurs in the presence of $10 \mu \mathrm{g}$ cycloheximide $\mathrm{ml}^{-1}$ or at $37^{\circ} \mathrm{C}$.

The type strain is $10-372^{\mathrm{T}} \quad\left(=\mathrm{CBS} \quad 9494^{\mathrm{T}}=\right.$ NCAIM $\mathrm{Y} 016667^{\mathrm{T}}$ ). Isolated from white wine in Zemplin, Hungary.

\section{Sequencing and phylogenetic analysis of the D1/D2 domain of the 26S rDNA}

To confirm the taxonomic separation of C. zemplinina from C. stellata, the variable D1/D2 domains of the $26 \mathrm{~S}$ rDNA of the four C. zemplinina isolates and C. stellata CBS $157^{\mathrm{T}}$ were amplified and sequenced. The amplified fragments of the C. zemplinina strains had identical nucleotide sequences, which differed from the homologous sequence of C. stellata $157^{\mathrm{T}}$ at 39 positions $(8 \cdot 1 \%$ sequence difference). Kurtzman \& Robnett (1998) observed that strains showing greater than $1 \%$ difference in the D1/D2 domain of the 26S rRNA are usually different species, whereas strains with zero to three nucleotide differences are either conspecific or sister species. Consistent with those observations, the C. zemplinina isolates studied here indeed represent a species distinct from C. stellata.

A similarity search in the NCBI database identified numerous additional species with 90-91\% identity over the entire length of the D1/D2 domain. The most similar sequence found was the D1/D2 domain of the unspecified organism Candida sp. EJ1. It differed only in two nucleotides from its counterpart in the C. zemplinina isolates. Using the generalization of Kurtzman \& Robnett (1998), C. zemplinina and Candida sp. EJ1 can be considered conspecific. The latter strain was isolated in California from botrytized grapes (Mills et al., 2002), demonstrating that C. zemplinina occurs in overripe botrytized grapes and musts in geographically distant localities. In the phylogenetic tree derived from the sequences of the most closely related species (Fig. 2), C. zemplinina $10-372^{\mathrm{T}}$ and Candida sp. EJ1 are in one clade with C. stellata and Candida davenportii. C. davenportii is a recently described osmotolerant yeast species isolated from a dead wasp (Stratford et al., 2002). 


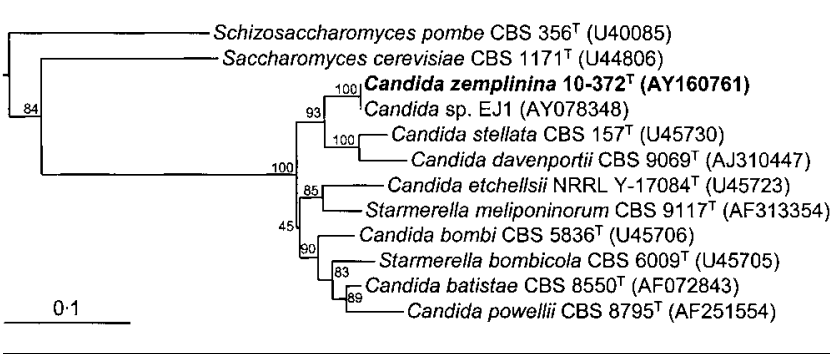

Fig. 2. Phylogenetic tree showing the relationship of C. zemplinina $10-372^{\top}$ with related yeast species. The dendrogram was derived from Fitch-Margoliash analysis of the nucleotide sequences of the D1/D2 domains of 26S rDNA. Saccharomyces cerevisiae and Schizosaccharomyces pombe were used as outgroups. Branch lengths are proportional to the number of nucleotide differences. The marker bar denotes relative branch length. Bootstrap values, expressed as percentages of 100 replications, are given at branch points. GenBank accession numbers are shown in parentheses. Starmerella meliponinorum is a recently described species associated with stingless bees (Teixeira et al., 2003).

\section{Sequencing and comparison of the $5 \cdot 85-I T S$ replicons}

PCR targeting the conserved 5.8S rDNA and its flanking regions results in amplicons which vary in length and sequence according to species (e.g. Shin et al., 1996; Valente et al., 1999; Granchi et al., 1999). Therefore, the relevant chromosomal regions of C. stellata CBS $157^{\mathrm{T}}$ and C. zemplinina $10-372^{\mathrm{T}}$ were amplified and sequenced. The alignment of the sequences revealed 11 substitutions between their $5 \cdot 8 \mathrm{~S}$ genes, which correspond to $92 \%$ identity and confirm the taxonomic separation of these species. Many more differences were found in the more variable ITS segments: at 20 positions in ITS1 and at 15 positions in ITS2. The $\mathrm{G} \rightarrow \mathrm{A}$ substitution at the $5^{\prime}$ ends of the conserved $5 \cdot 8 \mathrm{~S}$ sequences provides a possibility for differentiation between C. stellata and C. zemplinina by PCR-RFLP. Due to this difference, the restriction enzymes which recognize GATC (e.g. MboI) have three recognition sites in the C. stellata CBS $157^{\mathrm{T}}$ amplicon, but only two in the C. zemplinina $10-372^{\mathrm{T}}$ amplicon.

\section{Growth at high sugar concentrations and at low temperatures}

A characteristic feature of the yeast biota of fermenting sweet Tokaj wines is the high frequency of 'uvarum-type' Saccharomyces bayanus strains (Sipiczki et al., 2001; Naumov et al., 2002). These yeasts are usually osmotolerant and psychrotolerant and frequently overgrow Saccharomyces cerevisiae by the end of the fermentation. Since the C. zemplinina strains were also isolated from sweet botrytized musts, their growth was compared with that of C. stellata CBS $157^{\mathrm{T}}$, C. stellata DBPVG 6715, Saccharomyces cerevisiae S288c and Saccharomyces bayanus NCAIM $\mathrm{Y}_{00803^{\mathrm{T}}}\left(\mathrm{CBS} 380^{\mathrm{T}}\right)$ at various glucose concentrations and temperatures (selected data are shown in Table 1). The glucose concentrations tested were 2, 30, 40, 50 and $60 \%$ $(\mathrm{w} / \mathrm{v})$. The C. stellata strains could not grow in media supplemented with 40 or $50 \%$ glucose, whereas the C. zemplinina isolates showed a 5- to 30 -fold increase in optical density at $50 \%$ glucose and some growth even in the presence of $60 \%$ glucose. Fifty and $60 \%$ glucose also inhibited the growth of Saccharomyces cerevisiae S288c.

The effect of incubation temperature on growth was compared at 10, 20, 26 and $32^{\circ} \mathrm{C}$. At all temperatures, the C. zemplinina isolates grew much faster than the C. stellata strains. Their growth at $10^{\circ} \mathrm{C}$ was even faster than the growth of Saccharomyces cerevisiae and comparable to that of Saccharomyces bayanus.

Table 1. Effects of various conditions on the growth of strains

Values = optical density after 24 or $72 \mathrm{~h}$ /optical density at inoculation. Values are means of at least two determinations. All strains were grown in YPGL. Control, incubated at $26^{\circ} \mathrm{C}$ for $24 \mathrm{~h}$; glucose, medium supplemented with 50 or $60 \%$ glucose and incubated at $26^{\circ} \mathrm{C}$ for $24 \mathrm{~h} ; 10^{\circ} \mathrm{C}$, incubated for $72 \mathrm{~h}$; ethanol, medium supplemented with $8 \%$ ethanol and incubated at $26^{\circ} \mathrm{C}$ for $24 \mathrm{~h}$. ND, Not determined.

\begin{tabular}{|lccccc|}
\hline \multirow{2}{*}{ Strain } & \multirow{2}{*}{ Control } & \multicolumn{2}{c}{ Glucose } & \multirow{2}{*}{$\mathbf{1 0}{ }^{\circ} \mathbf{C}$} & \multirow{2}{*}{ Ethanol } \\
\cline { 3 - 4 } & & $\mathbf{5 0} \%$ & $\mathbf{6 0} \%$ & & \\
\hline Saccharomyces cerevisiae S288c & $82 \cdot 5$ & $1 \cdot 2$ & $1 \cdot 1$ & $11 \cdot 3$ & $28 \cdot 6$ \\
Saccharomyces bayanus NCAIM Y00803 ${ }^{\mathrm{T}}$ & $51 \cdot 1$ & $\mathrm{ND}$ & $\mathrm{ND}$ & $25 \cdot 0$ & $\mathrm{ND}$ \\
Candida stellata CBS $157^{\mathrm{T}}$ & $19 \cdot 7$ & $1 \cdot 1$ & $1 \cdot 0$ & $8 \cdot 0$ & $1 \cdot 4$ \\
Candida stellata DBPVG 6715 & $21 \cdot 3$ & $1 \cdot 2$ & $1 \cdot 2$ & $8 \cdot 1$ & $2 \cdot 5$ \\
Candida zemplinina $10-372^{\mathrm{T}}$ & $45 \cdot 3$ & $8 \cdot 3$ & $4 \cdot 8$ & $45 \cdot 0$ & $6 \cdot 6$ \\
Candida zemplinina $10-373$ & $42 \cdot 1$ & $5 \cdot 8$ & $3 \cdot 2$ & $21 \cdot 1$ & $6 \cdot 0$ \\
Candida zemplinina $10-374$ & $59 \cdot 1$ & $4 \cdot 2$ & $4 \cdot 0$ & $\mathrm{ND}$ & $14 \cdot 7$ \\
Candida zemplinina $10-375$ & $57 \cdot 1$ & $12 \cdot 8$ & $5 \cdot 5$ & $27 \cdot 5$ & $6 \cdot 5$ \\
\hline
\end{tabular}


These results indicate that C. zemplinina is osmotolerant and psychrotolerant and thus may be better suited than C. stellata to growth at high sugar concentrations and at low temperatures. These physiological properties can be particularly advantageous for propagation in botrytized grape musts, which usually have very high sugar concentrations and are fermented at low temperatures (usually below $15^{\circ} \mathrm{C}$ in Tokaj).

The C. zemplinina isolates also grew better in the presence of ethanol, although this tolerance does not make them real competitors of Saccharomyces bayanus var. uvarum or Saccharomyces cerevisiae in wine fermentation, because the increasing concentration of ethanol is still more inhibitory to them than to Saccharomyces (Table 1).

\section{ACKNOWLEDGEMENTS}

The author thanks Iren Pasztor for expert technical assistance. This work was supported in part by grants provided by the Hungarian Ministry of Education (FKFP 4/007/2002, NKFP 0322/2000) and the National Research Fund of Hungary (OTKA T031831).

\section{REFERENCES}

Barnett, J. A., Payne, R. W. \& Yarrow, D. (1990). Yeasts: Characteristics and Identification, 2nd edn. Cambridge: Cambridge University Press.

Ciani, M. \& Ferraro, L. (1998). Combined use of immobilized Candida stellata cells and Saccharomyces cerevisiae to improve the quality of wines. J Appl Microbiol 85, 247-254.

Ciani, M., Ferraro, L. \& Fatichenti, F. (2000). Influence of glycerol production on the aerobic and anaerobic growth of the wine yeast Candida stellata. Enzyme Microb Technol 27, 698-703.

Constanti, M., Reguant, C., Poblet, M., Zamora, F., Mas, A. \& Guillamon, J. M. (1998). Molecular analysis of yeast population dynamics: effect of sulphur dioxide and inoculum on must fermentation. Int J Food Microbiol 41, 169-175.

Farkaš, J. (1988). Technology and Biochemistry of Wine. New York: Gordon \& Breach.

Felsenstein, J. (1993). PHYLIP (phylogeny inference package), version 3.5c. Department of Genetics, University of Washington, Seattle, USA.

Granchi, L., Bosco, M., Messini, A. \& Vincenzini, M. (1999). Rapid detection and quantification of yeast species during spontaneous wine fermentation by PCR-RFLP analysis of the rDNA ITS region. J Appl Microbiol 87, 949-956.

Heard, G. M. \& Fleet, G. H. (1985). Growth of natural yeast flora during the fermentation of inoculated wines. Appl Environ Microbiol 50, 727-728.

Heyer, W.-D., Sipiczki, M. \& Kohli, J. (1986). Replicating plasmids in Schizosaccharomyces pombe: improvement of symmetric segregation by a new genetic element. Mol Cell Biol 6, 80-89.

Jackson, R. S. (2000). Wine Science. Principles, Practice, Perception. San Diego, CA: Academic Press.

Kreger-van Rij, N. J. W. (1984). The Yeasts. A Taxonomic Study. Amsterdam: Elsevier.
Krumbholz, G. (1931). Untersuchungen über osmophile Sprosspilze. III. Über einige kleinzellige Saccharomyceten. Arch Mikrobiol 2, 601-619.

Kurtzman, C. P. \& Robnett, C. J. (1998). Identification and phylogeny of ascomycetous yeasts from analysis of nuclear large subunit (26S) ribosomal DNA partial sequences. Antonie van Leeuwenhoek 73, 331-371.

Mills, D. A., Johannsen, E. A. \& Cocolin, L. (2002). Yeast diversity and persistence in botrytis-affected wine fermentations. Appl Environ Microbiol 68, 4884-4893.

Naumov, G. I., Naumova, E. S., Antunovics, Z. \& Sipiczki, M. (2002). Saccharomyces bayanus var. uvarum in Tokaj wine-making of Slovakia and Hungary. Appl Microbiol Biotechnol 59, 727-730.

O'Donnell, K. (1993). Fusarium and its near relatives. In The Fungal Holomorph: Mitotic, Meiotic and Pleomorphic Speciation in Fungal Systematics, pp. 225-233. Edited by D. R. Reynolds \& J. W. Taylor. Wallingford, UK: CAB International.

Page, R. D. M. (1996). TREEVIEW: an application to display phylogenetic trees on personal computers. Comput Appl Biosci 12, 357-358.

Rosini, G., Federici, F. \& Martini, A. (1982). Yeast flora of grape berries during ripening. Microb Ecol 8, 83-89.

Schutz, M. \& Gafner, J. (1994). Dynamics of the yeast strain population during spontaneous alcoholic fermentation determined by CHEF gel electrophoresis. Lett Appl Microbiol 19, 253-257.

Shin, K. S., Hong, S. D. \& Bae, K. S. (1996). The significance of ITS-RFLPs and Coenzyme $\mathrm{Q}$ system in determining taxonomic relationships among Candida species. J Gen Appl Microbiol 42, 481-491.

Sipiczki, M., Romano, P., Lipani, G., Miklos, I. \& Antunovics, Z. (2001). Analysis of yeasts derived from natural fermentation in a Tokaj winery. Antonie van Leeuwenhoek 79, 97-105.

Soden, A., Francis, I. L., Oakey, H. \& Henschke, P. A. (2000). Effects of co-fermentation with Candida stellata and Saccharomyces cerevisiae on the aroma and composition of Chardonnay wine. Aust J Grape Wine Res 6, 21-30.

Stratford, M., Bond, C. J., James, S. A., Roberts, I. N. \& Steels, H. (2002). Candida davenportii sp. nov., a potential soft-drinks spoilage yeast isolated from a wasp. Int J Syst Evol Microbiol 52, 1369-1375.

Teixeira, A. C. P., Marini, M. M., Nicoli, J. R., Antonini, Y., Martins, R. P., Lachance, M.-A. \& Rosa, C. A. (2003). Starmerella meliponinorum sp. nov., a novel ascomycetous yeast species associated with stingless bees. Int J Syst Evol Microbiol 53, 339-343.

Thompson, J. D., Higgins, D. G. \& Gibson, T. J. (1994). CLUSTAL W: improving the sensitivity of progressive multiple sequence alignment through sequence weighting, position-specific gap penalties and weight matrix choice. Nucleic Acids Res 22, 4673-4680.

Valente, P., Ramos, J. P. \& Leoncini, O. (1999). Sequencing as a tool in yeast molecular taxonomy. Can J Microbiol 45, 949-958.

van der Walt, J. P. \& Yarrow, D. (1984). Methods for the isolation, maintenance, classification and identification of yeasts. In The Yeasts: a Taxonomic Study, pp. 45-104. Edited by N. J. W. Kreger-van Rij. Amsterdam: Elsevier.

White, T. J., Burns, T., Lee, S. \& Taylor, J. (1990). Amplification and sequencing of fungal ribosomal RNA genes for phylogenetics. In PCR Protocols. A Guide to Methods and Applications, pp. 315-322. Edited by M. A. Innis, D. H. Gelfand, J. J. Snisky \& T. J. White. San Diego, CA: Academic Press. 